\title{
A viabilidade da utilização do combustível biodiesel nas viaturas da Academia da Força
}

\section{Aérea Brasileira}

\author{
Manoela Alves Pires ${ }^{1}$ \\ Rafael Felix Raposo da Costa Pereira ${ }^{2}$
}

\section{Resumo}

O Biodiesel, por ser um combustível biodegradável derivado de fontes renováveis, vem sendo alvo de diversos temas relacionados à sua participação inovadora na matriz energética mundial. Devido às reservas dos combustíveis fósseis estarem se tornando cada vez mais escassas e os impactos ambientais causados por estes serem significativos, torna-se necessário, uma avaliação da utilização do biodiesel tendo em vista aspectos: econômicos, sociais e ambientais. O Brasil é um grande produtor de oleaginosas, matéria-prima para produção de biodiesel, e ao mesmo tempo possui um déficit energético no qual se refere ao diesel, assim, torna-se importante o desenvolvimento de alternativas para suprir esta necessidade e diminuir a poluição causada pelo uso dos combustíveis fósseis. Sendo assim, esta pesquisa teve o objetivo de verificar, por meio de uma revisão bibliográfica e pesquisa de campo feita à Seção de Transporte da Academia da Força Aérea (AFA) a viabilidade de substituir o combustível diesel pelo biocombustível biodiesel. Os resultados mostraram que economicamente não há custos para fazer a substituição do diesel para biodiesel, sendo também o custo do próprio combustível equivalente ao diesel e o biodiesel um combustível promissor do ponto de vista ambiental.

Palavras-chave: Diesel. Biocombustível. Meio ambiente. Fontes renováveis.

\section{Introdução}

O aquecimento global, que nada mais é do que "o aumento das temperaturas médias do planeta Terra, provocando alterações no clima de algumas regiões, intensificando fenômenos naturais, como furacões e secas, entre outros" (VEIGA, 2008), o qual vem

1 - Oficial do Magistério em Química na Academia da Força Aérea Brasileira. Graduada em Química pela Faculdades Oswaldo Cruz, Mestre e Doutora em Ciências pela FZEA/USP. Email: manoela.alvespires@ hotmail.com.

2 - Oficial Aviador formado pela Academia da Força Aérea Brasileira. Graduado em Administração e Ciências militares pela Academia da Força Aérea (AFA). E-mail: raposorfrcp@ fab.mil.br. 
ocasionando danosas modificações nos ecossistemas terrestres, como "desertificação, derretimento das geleiras dos pólos do planeta, migrações em massa de pessoas, problemas na agricultura, epidemias e desastres ambientais" (VEIGA, 2008). Segundo o Painel Intergovernamental de mudanças do Clima, o $\mathrm{CO}_{2}$ é o principal "culpado" pelo aquecimento global, sendo o gás mais emitido (aproximadamente 77\%) pelas atividades humanas que estão diretamente ligadas à queima de combustíveis fósseis (VEIGA, 2008).

A fim de resolver tais problemas, muitos estudiosos dentre eles engenheiros, economistas, cientistas vêm apostando no desenvolvimento do biodiesel como substituto direto do diesel, pois se trata de um combustível agrícola, biodegradável, não tóxico, o qual é obtido "a partir de óleos vegetais, sebo de origem animal, óleo de frituras e da matéria graxa encontrada nos esgotos municipais" (D'ARCE, 2005), que pode ser utilizado em motores Diesel em misturas com o óleo diesel mineral sem a necessidade de adaptação aos motores reduzindo a emissão de poluentes atmosféricos nos grandes centros urbanos (MACEDO e NOGUEIRA, 2004).

No Brasil, essa ideia da possível substituição parcial do óleo diesel não é nova. Fazendo um paralelo ao Proálcool, que pode ser considerado o mais bem sucedido programa de biocombustíveis no mundo. Em 2004, foi criado no Brasil o Programa Nacional de Produção e Uso do Biodiesel (PNPB), que vem apresentando bons resultados, porém enfrenta o mesmo problema que os programas anteriores: a viabilidade econômica da produção e da utilização do biodiesel em grande escala sem necessidade de grandes subsídios e/ou isenção de impostos por parte do governo (MACEDO e NOGUEIRA, 2004).

Nesse contexto, este trabalho abordará os principais conceitos relacionados ao Biodiesel, explanará de forma geral a situação deste no Brasil, além de explicitar as vantagens econômicas, sociais e ambientais atreladas à utilização dessa possível solução energética. E por fim, será realizada uma análise de um possível uso do biodiesel nas viaturas da Academia da Força Aérea através de dados coletados na Seção de Transporte da mesma.

\section{Revisão Bibliográfica}

O cenário energético mundial indica que vivemos em uma situação de elevada dependência dos combustíveis fósseis como fonte de energia. Os combustíveis fósseis são 
recursos energéticos não renováveis, e que, portanto, tendem a se esgotar com o passar do tempo. Apesar de ainda existirem novas reservas a serem descobertas e exploradas, o custo para essa exploração tende a aumentar à medida que essas se tornam cada vez menos acessíveis havendo a necessidade de maior tecnologia para a exploração dessas reservas (BOTELHO, 2012).

Segundo estatística da Bristish Petroleum (Tabela 1) a América Central e Sul tem o segundo maior percentual de petróleo do Mundo, entretanto, contando apenas com 19,7\%, com duração estimada de aproximadamente 48 anos (BP, 2013).

Tabela 1 - Concentração geográfica de petróleo em 2012

\begin{tabular}{lc}
\hline Região & Petróleo (\%) \\
\hline Oriente Médio & 48,4 \\
Américas Central e do Sul & 19,7 \\
América do Norte & 13,2 \\
Europa e Eurásia & 8,4 \\
África & 7,8 \\
Ásia do Pacífico & 2,5 \\
\hline
\end{tabular}

Fonte: BP, 2013

Devido à esgotabilidade e também da geopolítica das reservas dos combustíveis fósseis a sua substituição por combustíveis renováveis, os biocombustíveis, se faz necessária. Segundo Goldemberg (1998) essa real substituição dos fósseis pelos renováveis é muito mais pelos impactos ambientais do que pela falta de oferta do mesmo.

Apesar do Brasil ser um país com participação ativa e expressiva de biocombustíveis, principalmente da matriz etanol, o país ainda é dependente do consumo de derivados de petróleo, sobretudo do óleo diesel. A Empresa de Pesquisa Energética estimou que em 2010 o óleo diesel foi responsável pelo fornecimento de 48,6\% (Tabela 2) de toda energia consumida pelo setor de transportes no país (EPE, 2011). 
Tabela 2 - Consumo de energia pelo setor de transportes no Brasil em 2010

\begin{tabular}{lc}
\hline & $\%$ \\
\hline Óleo diesel & 48,6 \\
Gasolina Automotiva & 25,2 \\
Etanol hidratado & 11,9 \\
Etanol anidro & 5,5 \\
Querosene de aviação & 4,6 \\
Gás natural & 2,5 \\
Óleo combustível & 1,4 \\
Eletricidade & 0,2 \\
Gasolina de aviação & 0,1 \\
\hline
\end{tabular}

Fonte: EPE, 2011

Biocombustível é um termo genérico dado aos combustíveis produzidos a partir da extração de matéria orgânica, fontes renováveis, ou seja, pelos produtos naturais ou provenientes de origem animal. $\mathrm{Na}$ atualidade, os biocombustíveis mais conhecidos são: o bioetanol, o biogás e o biocarburantes. Dentre as fontes mais conhecidas no mundo, estão as sementes de girassol, mamona, palma, soja, milho e o sebo bovino os quais servem para produção do biodiesel (FONTANA, 2011).

Segundo a Agência Nacional do Petróleo, biodiesel é um “Combustível natural usado em motores diesel, produzido através de fontes renováveis, que atende as especificações técnicas estabelecidas" (BRASIL, 2009).

O biodiesel é obtido através do processo de transesterificação, que é uma reação química na qual os triacilgliceróis presentes nos óleos e nas gorduras reagem com um álcool de baixo peso molecular na presença de um catalisador para formar ésteres alquílicos de ácidos graxos (biodiesel) e glicerol (glicerina) como produto, onde a glicerina é separada da gordura vegetal ou do óleo vegetal, gerando assim dois produtos: o éster, nome químico do biodiesel e a glicerina que é bastante usada no mercado de sabões. Como a célula vegetal é formada por três moléculas de ácidos graxos ligados a uma molécula de glicerina, o processo retira a glicerina para que o óleo se transforme em combustível (óleo mais fino e menos viscoso), pois cerca de $20 \%$ da célula vegetal é formada por glicerina (PARENTE, 2003). 
O Brasil tem uma característica peculiar em relação aos países que produzem o biocombustível, tal qual: tem a vantagem de possuir uma gama de 25 fontes alternativas vegetais, enquanto outros países possuem apenas uma ou duas fontes para essa produção (FONTANA, 2011).

De um determinado ponto de vista, qualquer vegetal produtor de óleo pode ser empregado para a produção de biodiesel, tendo em vista que o óleo extraído transfere para o biodiesel suas propriedades (FONTANA, 2011).

Contudo, nem todos os vegetais trariam vantagens se houvesse produção em larga escala, pois necessitaria de uma grande intervenção tecnológica para adequar a qualidade do seu óleo aos padrões exigidos. Dentre essas outras fontes podemos destacar a canola, o girassol, o amendoim, algodão, palmiste, e coco (FONTANA, 2011).

Assim como a soja, o sebo possui uma vasta região de produção, concentrandose principalmente sobre o centro-oeste (Mato Grosso do Sul e Mato Grosso do Sul), e em seguida o sudeste (Minas Gerais), destacando-se tanto por ser o segundo maior rebanho bovino do mundo, como pela sua logística ser bastante desenvolvida (FONTANA, 2011).

O biodiesel produzido com o sebo bovino apresenta inúmeras vantagens se comparado com o produzido a partir do óleo de soja, como por exemplo: maior número de cetano que o diesel mineral e que o biodiesel de soja (65 x 43 e 65 x 55 respectivamente); maior estabilidade; não compete com alimento; menos inflamável (ponto de fulgor maior que $130 \mathrm{C})$; e a estabilidade oxidativa superior ao biodiesel de soja. Possuía apenas uma única característica que causava preocupação, o ponto de entupimento de filtro a frio (CFPP na sigla em inglês), que foi perfeitamente contornada com a mistura do sebo com óleos líquidos no período de inverno (ALMEIDA, 2008).

Existe também, a produção de biodiesel a partir do óleo extraído de microalgas, tendo como principais as diatomáceas (Skeletonema costatum), flageladas (Isochrysis galbana) e a clorococaleana (Chlorella spp), que representa uma alternativa promissora em longo prazo, todavia, essa tecnologia ainda está em fase de desenvolvimento, necessitando ganhar escala para que possa se tornar viável, economicamente falando, o que não deve ocorrer no curto e médio prazo (FONTANA, 2011). 
No curto prazo, uma possível solução que pode ser apresentada é a utilização de matérias primas residuais tais como: óleos utilizados em processo de frituras e materiais graxos presentes nos esgotos. Essas são matérias primas residuais e de baixa qualidade, as quais podem ser obtidas a custos reduzidos (MATSUOKA, 2009).

O óleo diesel é uma fração combustível derivada do petróleo diretamente do processo de destilação atmosférica, sua composição é de hidrocarbonetos, média de C9 a C25, o diesel é empregado nos motores de combustão interna onde a ignição se dá por compressão, nos motores de ciclo diesel. Um dos pontos negativos é a ocorrência de compostos sulfurados, o que na queima gera anidrido sulfuroso $\left(\mathrm{SO}_{2}\right)$, o qual expelido no ar úmido ou chuvoso gera a chuva ácida, outro ponto é a pequena quantidade de hidrocarbonetos, apesar de pequena, é carcinogênico. $\mathrm{O}$ biodiesel por sua vez é uma mistura heterogênea composta de álquil ésteres de ácidos graxos de cadeias longa, derivados de óleos vegetais ou de gorduras animais, menos poluentes que o diesel, derivado de biomassa renovável obtida por várias fontes vegetais ou animais renováveis, facilita a combustão dos hidrocarbonetos por conter um teor de $10 \%$ de oxigênio e é também utilizado nos motores de combustão interna por compressão (FONTANA, 2011).

Outras vantagens advindas do biodiesel são: mais seguro do que o diesel de petróleo, pois apresenta ponto de fulgor (temperatura de combustão do combustível) na sua forma pura de $150^{\circ} \mathrm{C}$ contra $45^{\circ} \mathrm{C}$ do diesel comum; apresenta uma combustão mais completa; não requer armazenamento especial, podendo, sua armazenagem e distribuição, serem realizadas utilizando a mesma infraestrutura que a do óleo diesel convencional; e funciona em motores convencionais sem qualquer necessidade de modificações seja do sistema de injeção ou do motor de combustão propriamente dito (FONTANA 2011).

Além de todas as vantagens da utilização do biodiesel a situação de dependência energética do óleo diesel, principalmente no setor de transportes brasileiro, não é desejável do ponto de vista estratégico e nem ambiental, uma vez que, não é um combustível renovável, é altamente poluente e o país depende de importações (BOTELHO, 2012).

Segundo pesquisa realizada pela CETESB (2009) sobre a poluição atmosférica na Região Metropolitana do Estado de São Paulo a emissão de gases poluentes provenientes da queima de óleo diesel são as mais significativas, responsáveis pela emissão de $82 \%$ dos 
óxidos de nitrogênio (NOx), 49\% dos óxidos de enxofre (SOx) e 71\% de material particulado emitidos na região naquele ano.

Segundo Parente (2003) os impactos ambientais das emissões são o aspecto mais importante referente ao uso de qualquer combustível, pois estão associados aos danos causados ao meio ambiente e também à saúde humana. Ao reduzir as emissões de poluentes atmosféricos, promovendo a melhoria da qualidade do ar, principalmente nas grandes cidades, o uso do biodiesel pode evitar a ocorrência de custos de diversas ordens, incluindo aqueles relacionados à saúde pública.

Miraglia (2002) apresenta dados sobre a mortalidade média infantil em 1991(até cinco anos) e de idosos em 1994 (acima de 65 anos de idade) no município de São Paulo, por doenças respiratórias que podem ser associadas à poluição atmosférica (Tabela 3).

Tabela 3 - Mortalidade associada a poluição atmosférica em crianças (1991) e idosos (1994)

\begin{tabular}{|c|c|c|}
\hline & $\begin{array}{l}\text { Média diária de } \\
\text { óbitos }\end{array}$ & $\begin{array}{l}\text { Participação na } \\
\text { mortalidade total da faixa } \\
\text { etária }\end{array}$ \\
\hline Doenças respiratórias (crianças) & 2,96 & $36,2 \%$ \\
\hline Doenças respiratórias (idosos) & 12,84 & $18,6 \%$ \\
\hline
\end{tabular}

Fonte: Adaptado de Miraglia, 2002

A U. S. Environmental Protection Agency (EPA) realizou diferentes ensaios comparando a emissão de poluentes atmosféricos de veículos movidos a diesel e outros veículos com adição de biodiesel no diesel em \%, por exemplo, B5, igual a 5\% de biodiesel no diesel, demonstrando que há uma redução significativa de poluentes com aumento de biodiesel na sua composição ou até mesmo em sua substituição total (B100) (Tabela 4). 
Tabela 4 - Variação da emissão de poluentes de diferentes misturas de diesel e biodiesel

\begin{tabular}{lcccc}
\hline Poluente & B2 & B5 & B20 & B100 \\
\hline Monóxido de Carbono & $-1,0 \%$ & $-3,0 \%$ & $-12,0 \%$ & $-48,0 \%$ \\
Hidrocarbonetos totais & $-2,0 \%$ & $-5,0 \%$ & $-20,0 \%$ & $-67,0 \%$ \\
Óxidos de nitrogênio & $0,2 \%$ & $0,5 \%$ & $2,0 \%$ & $10,0 \%$ \\
Materiais particulados & $-1,0 \%$ & $-3,0 \%$ & $-12,0 \%$ & $-47,0 \%$ \\
Óxidos de enxofre & $-2,0 \%$ & $-5,0 \%$ & $-20,0 \%$ & - \\
& & & & $100,0 \%$ \\
\hline
\end{tabular}

Fonte: EPA, 2012

A substituição total do diesel pelo biodiesel é extremamente significativa no âmbito de impacto ambiental, a redução de poluentes pode diminuir em até $100 \%$ de óxidos de enxofre, $67 \%$ de hidrocarbonetos totais, $48 \%$ de monóxido de carbono e $47 \%$ de materiais particulados, totalizando uma redução total de $267 \%$ menos poluição do que é gerado atualmente. Ocorrendo apenas, um acréscimo de 10,0\% de óxidos de nitrogênio, devido a influencia nas temperaturas alcançadas na câmara de combustão do motor, o que pode ser diminuído com o uso de catalisadores (BOTELHO, 2012).

Outro aspecto ambiental importante sobre o uso de biodiesel como combustível é que esse é facilmente biodegradável em ambientes aquáticos e terrestres, e a sua toxicidade é consideravelmente menor do que do óleo diesel. Assim, o biodiesel poderia provocar menores impactos ambientais em casos de derramamentos ou vazamentos acidentais (BOTELHO, 2012).

No âmbito econômico e social, tem-se: Aumenta a vida útil dos motores por ser mais lubrificante; Possibilitará o surgimento de um novo mercado; A agregação de valores às matérias-primas; A geração de empregos; A redução das importações de petróleo e óleo diesel refinado; A melhoria na balança comercial; $\mathrm{O}$ incremento nas economias regionais; $\mathrm{A}$ possibilidade de participação do pequeno agricultor e a fixação do homem ao campo; e Podese contabilizar também a possível melhor distribuição de renda e o incentivo à agricultura familiar (FONTANA, 2011). 
A grande desvantagem do biodiesel em relação ao diesel é o seu custo na compra, o litro do diesel é de $\mathrm{R} \$ 1,74$ e do biodiesel $\mathrm{R} \$ 2,24$ (mês de referência: agosto de 2013), entretanto, segundo Fontana (2011), a somatória de todos os impostos federais que incidem sobre o biodiesel (PIS/COFINS) é de R $\$ 0,222 /$ litro, os quais podem ser diminuídos a $32 \%$ ( $\mathrm{R} \$ 0,151)$, o que o tornaria mais competitivo economicamente com o diesel, totalizando o valor em $\mathrm{R} \$ 1,52 /$ litro.

O custo do biodiesel está diretamente relacionada a sua produção industrial: uma maneira de se reduzir o custo de produção do biodiesel em até $30 \%$ é investir em economia de escala. Outra complicação é que a viabilidade econômica da indústria de biodiesel é extremamente sensível ao preço dos subprodutos gerados na produção que são, atualmente, a torta remanescente da extração do óleo e o glicerol. A torta remanescente do óleo pode ser diretamente direcionada para ração animal como fonte de proteína e o glicerol tem aplicação em diversos segmentos como: indústria alimentícia, cosméticos, tabaco, papéis e na produção de dinamites. Entretanto, esse produto só tem valor agregado em relação a sua pureza, uma vez que, a grande maioria do biodiesel produzido no Brasil utiliza como matériaprima o metanol, o qual é altamente tóxico, sendo assim, o subproduto glicerol gerado no processo pode conter impurezas do metanol e com isso ter seu valor reduzido (CAMARGOS, 2005).

Com o aumento do preço do petróleo e com incentivo governamental o crescimento na produção de biodiesel é uma tendência social, econômica e principalmente ambiental.

\section{Metodologia}

Foi realizada pesquisa de campo onde mediante questionário de perguntas objetivas sobre o consumo do combustível diesel nas viaturas da Academia da Força Aérea via Seção de Transporte (STR). Foram solicitadas respostas relacionadas ao consumo do combustível diesel por nove perguntas simples. 


\section{Resultados e Discussões}

O questionário realizado obteve os dados da STR de total de viaturas movidas a diesel $(n=68)$, consumo do combustível diesel e outras informações pertinentes, descritas nas Tabelas 5 e 6.

Tabela 5 - Consumo Anual de Diesel pelas viaturas da Academia da Força Aérea

\begin{tabular}{ccc}
\hline $\mathbf{2 0 1 1}$ & $\mathbf{2 0 1 2}$ & Média Anual \\
\hline $\mathbf{1 8 2 . 5 2 4}$ Litros & 174.620 Litros & 178.572 \\
\hline
\end{tabular}

Fonte: $\mathrm{O}$ autor (2012)

Tabela 6 - Cálculos teóricos do gasto de diesel na Academia da Força Aérea

\section{Consumo Mensal de Diesel pelas Viaturas da AFA em Litros}

Valor do Litro do Diesel em R\$

Cálculo Estimado do gasto de diesel pelas Viaturas da AFA por mês em $\mathrm{R} \$$

Cálculo Estimado do gasto de diesel pelas Viaturas da AFA por ano em $\mathrm{R} \$$

Fonte: $\mathrm{O}$ autor (2012)

Sendo o possível custo do biodiesel, sem os impostos atribuídos de $\mathrm{R} \$ 1,52$ o litro. A comparação do gasto com as viaturas da Academia da Força Aérea utilizando diesel e o custo provável na substituição desse combustível por biodiesel pode ser observado na Figura 1.

Como se pode observar na Figura 1, a substituição do combustível diesel por biodiesel do ponto de vista econômico não é significativo, porém, seria possível uma economia de aproximadamente $\mathrm{R} \$ 6.250,00 / \mathrm{ano}$, com o custo do biodiesel reduzido de impostos, porém, o custo seria maior se o mesmo não obtivesse redução de impostos e comprado a $\mathrm{R} \$ 2,24 /$ itro, aumentando em aproximadamente $\mathrm{R} \$ 90.000,00$ por ano o custo de combustível. Fontana (2011) afirmou que não há qualquer custo adicional para substituir o diesel por biodiesel, nem do ponto de vista de motor dos veículos ou mesmo de armazenamento do combustível. 
Figura 1 - Comparação do custo, em reais $(\mathrm{R} \$)$, do combustível diesel da STR e possível custo utilizando o combustível biodiesel

\section{Custo Diesel x Biodiesel}

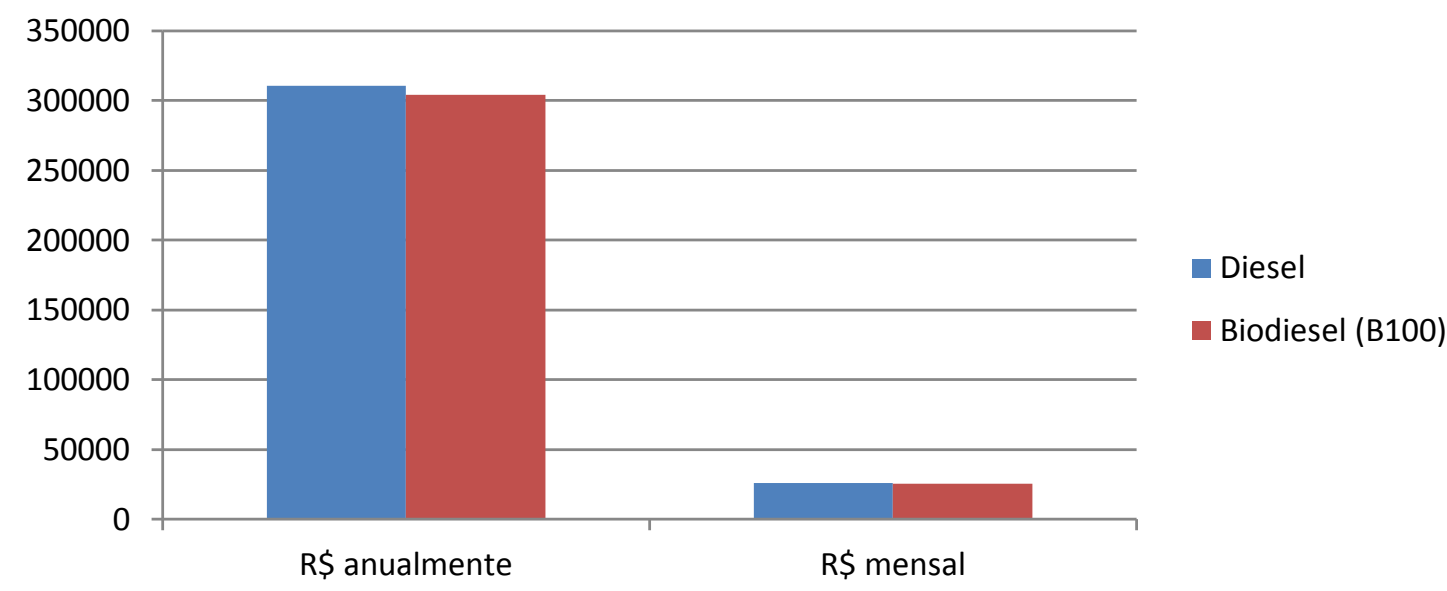

Fonte: O autor (2012)

Segundo Parente (2003), o aspecto mais importante referente à utilização de qualquer combustível é o aspecto ambiental. Na Figura 2 a utilização do biodiesel por diesel do ponto de vista ambiental é extremamente significativo, como do poluente SOx (dióxido de enxofre) ocorrendo uma diminuição de $-100 \%$ quando comparado o B100 (biodiesel 100\%) com o B5 (diesel + biodiesel 5\%).

Grupo de Trabalho Interministerial (GTI, 2003) concluiu que o Brasil poderia economizar aproximadamente $\mathrm{R} \$ 75,6$ milhões por ano, com enfermidades relacionadas a poluentes, as quais são tratadas nos diversos hospitais das dez principais cidades do país.

Além de todos esses fatores, uma fonte para produção de biodiesel é de óleos e gorduras gerados na produção de alimentos, sendo esses resíduos gerados na cozinha da AFA que, por sua vez, poderiam ser utilizados para produção do próprio biodiesel. 
Figura 2 - Comparação da diminuição de poluentes utilizando biodiesel (\%)

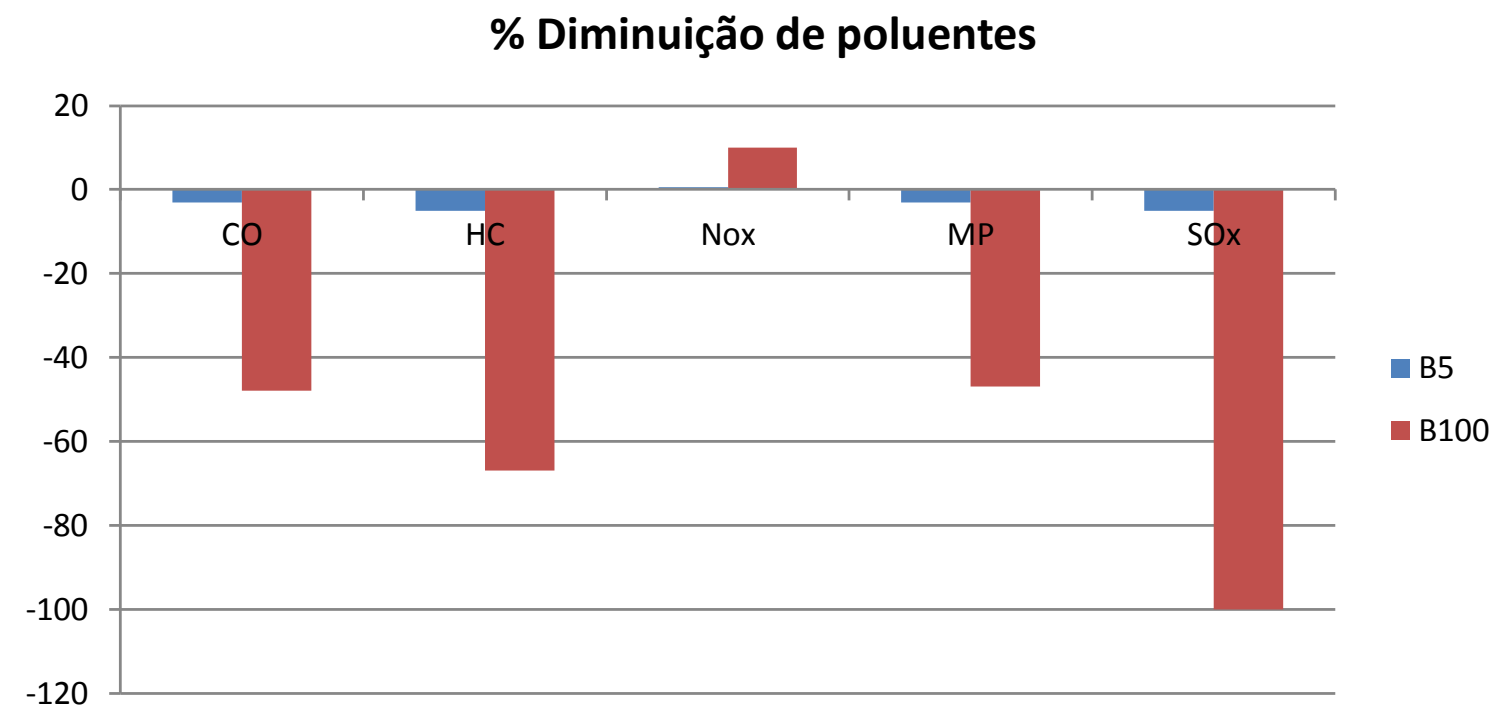

Fonte: $\mathrm{O}$ autor (2012)

\section{Conclusão}

A utilização de biodiesel como combustível tem apresentado um potencial promissor no mundo inteiro. Primeiramente, pela sua enorme contribuição ao meio ambiente, com a redução qualitativa e quantitativa dos níveis de poluição ambiental, e, em segundo lugar, como fonte estratégica de energia renovável em substituição ao óleo diesel e outros derivados do petróleo.

A partir dos resultados obtidos neste estudo, conclui-se que, no âmbito econômico, os dois combustíveis se equiparam em relação ao custo de obtenção, quando houver redução de impostos na sua compra, entretanto, não sendo possível essa redução o custo do biodiesel torna-se elevado. Para uma substituição total do diesel para o biodiesel não há necessidade de mais despesas em relação à modificação na parte mecânica das viaturas e sua estocagem. Contudo, biodiesel se mostra bastante promissor dos pontos de vista ambiental e social, pois a emissão de partículas nocivas à atmosfera diminui significativamente em comparação ao diesel, além de proporcionar uma melhoria na qualidade social da população da região da AFA, e a defesa de uma Força Aérea com responsabilidade social e ambiental preocupada com o futuro da humanidade. 


\section{Referências}

ALMEIDA, S. C. A .Technical and economic viability of the use of biodiesel indiesel engines (2008). Disponível em: http://146.164.33.61/silviocarlos/Congressos/TRB2385.pdf. Acessado em: 18/abril/2013

BRASIL. Ministério do Meio Ambiente. Ministério da Agricultura, Pecuária e Abastecimento. Ministério da Ciência e Tecnologia. Ministério de Minas e Energia. Ministério do Desenvolvimento, Indústria e Comércio Exterior. DIRETRIZES DE POLÍTICA DE AGROENERGIA. Brasília, 2009. 123 p.

BOTELHO, C.A.V.A. Viabilidade técnica e aspectos ambientais do biodiesel etílico de óleos residuais de fritura. 2012. 123f. Dissertação (Mestrado em Ciências) - Universidade de São Paulo, São Paulo, 2012.

CAMARGOS, R. R. S. Avaliação da viabilidade de se produzir biodiesel através da transesterificação de óleos de grãos de café defeituosos. 2005. 105f. Dissertação (Mestrado em Engenharia Química) - Universidade Federal de Minas Gerais, Belo Horizonte, 2005.

CETESB: COMPANHIA AMBIENTAL DO ESTADO DE SÃO PAULO. Relatório de qualidade do ar no Estado de São Paulo 2008. São Paulo: CETESB, 2009.

D’ARCE, M. A. B. R. matérias-primas oleaginosas e biodiesel. São Paulo : ESALQ/USP, setor de açúcar e álcool, 2005.

EPA: United States ENVIRONMENTAL PROTECTION AGENCY. A Comprehensive Analysis of Biodiesel on Exhaust Emissions. Draft Technical Report, 2002.

EPE: EMPRESA DE PESQUISA ENERGÉTICA: Balanço Energético Nacional 2010 Ano Base 2010. Rio de Janeiro: EPE, 2011. 
FONTANA, J. D., - BIODIESEL para leitores de 9 a 90 anos; comentários de Univaldo Vedana - Curitiba: Ed. UFPR, 2011.

GOLDEMBERG, J. Energia, meio ambiente e desenvolvimento. São Paulo: EDUSP, 1998.

GTI (Grupo de Trabalho Interministerial) . Relatório final do grupo de trabalho interministerial encarregado de apresentar estudos sobre a viabilidade de utilização de óleo vegetal - biodiesel como fonte de energia. Governo Federal, 2003.

MACEDO, I.; NOGUEIRA, L.A.H..Avaliação do biodiesel no Brasil. In:NAE( Núcleo de Assuntos Estratégicos da Presidência). Biocombustíveis. Brasília, Cadernos NAE n2,seção 1, :NAE ,2004.

MATSUOKA, C.R. Qualidade do óleo de fritura da mandioca: correlação entre dado analíticos para a determinação do ponto de descarte. 2009156 p. Dissertação (Mestrado) - Escola Superior de Agricultura “Luiz de Queiroz” da Universidade de São Paulo,Piracicaba, 2009.

MIRAGLIA, S. G. E. K. O ônus da poluição atmosférica sobre a população do município de São Paulo. 2002. 126p. Tese (Doutorado em Medicina) - Faculdade de Medicina de São Paulo, São Paulo, 2002.

PARENTE, E.J.S. Biodiesel:uma aventura tecnológica num pais engraçado.Fortaleza : Tecbio 2003.

VEIGA, J. E. Aquecimento Global: frias contendas científicas. São Paulo: Editora SENAC, 2008. 
The feasibility of using biodiesel in vehicles of the Brazilian Air Force Academy

\begin{abstract}
The Biodiesel, for being a biodegradable fuel derivative of sources renewed, comes being goal of diverse related subjects its innovative participation in world-wide the energy matrix. Had the reserves of scarcer fossil fuels to be if becoming each time and the ambient impacts caused by these to be significant, becomes necessary, an evaluation of the use of biodiesel in view of aspects: economic, social and ambient. Brazil is the highest producer of oil and at the same time have an energy deficit in which refers to diesel, it is important to develop alternatives to meet this need, contribute to increase the income of the poorest population and reduce pollution the use of fossil fuels. For this reason, the objective of this research was to evaluate by review and question made on Transport Section from Air Force Academy in order to check the availability to substitute diesel fuel for biodiesel. The results showed that economic there was no significant difference when applied taxes reduction and there was nothing cost in terms of structure or motor to change the fuels, biodiesel shown promising points of environmentally and socially.
\end{abstract}

Keywords: Diesel. Biofuel. Environment. Renewable source. 